\title{
The Role of Motor Activity in the Self-Esteem of Primary School Pupils
}

\author{
MANUELA VALENTINI ${ }^{1, *}$, ELISA DI MASSA ${ }^{2}$, GIOVANNA TROIANO ${ }^{2}$, ARIO FEDERICI $^{3}$ \\ ${ }^{1}$ Department of Human Sciences, University of Urbino "Carlo Bo", Urbino, Italy \\ ${ }^{2}$ University of Urbino "Carlo Bo", Urbino, Italy \\ ${ }^{3}$ Department of Bio-molecular Sciences, University of Urbino "Carlo Bo", Urbino, Italy \\ *Corresponding author: manuela.valentini@uniurb.it
}

Received December 28, 2012; Revised February 07, 2013; Accepted March 09, 2013

\begin{abstract}
The purpose of this study is to analyze the importance of motor activity in the increase of self-esteem in Primary School pupils. To have positive self-esteem is a significant aspect of the growth of a person as a whole [9]. Depending on the level of self-esteem, individuals take risks in various situations and respond to failure in different ways [2]. Nine year old children are moving towards the threshold of adolescence, a time when physical change is predominant. Therefore, aiming at the development of self-esteem through motor activity has the purpose of building confidence in children who are about to face these changes. In this study, $\mathrm{X}$ classes were given two identical tests: the MOVIT test [7], evaluating physical perceptions and capabilities, and the TMA test [5], evaluating global and specific self-esteem. Pupils were tested in October and then in the following March. During this period the target group worked on autonomy and on interpersonal relationships by means of planned activities involving team-play. The average test results of the two groups demonstrated that the work group had improved significantly both in the physical field and in self-esteem with respect to the control group, therefore planned motor activities are effective in building self-esteem in Primary school pupils. Motor activity is of vital importance for the development of capacity and cognitive skills and with specific reference to the analyzed case, motor activity influences the growth of self-esteem, leading the subject to a full physical and mental development.
\end{abstract}

Keywords: children, primary school, motor activity, self- esteem, socialization, development

\section{Introduction}

The objective of this research is to demonstrate how greatly motor activity influences the self esteem of a child. The relationship between self esteem and physicality is evident in the ages of greatest evolution[8]. For a child, physical performance, ability in group games and sport is of primary importance. If s/he does not feel adequate with respect to others, his or her self esteem will decrease profoundly [21]. A child who feels comfortable and adequate physically will improve his or her level of self esteem [11]. Non verbal language is the first area through which the internal self manifests itself and is the most spontaneous representation of any type of discomfort or malaise [20]. The construction of self esteem relates in different ways to the body through the image of oneself both in physical terms but also in terms of physical performance such as the ability to perform well in situations such as games of competitions with children of the same age [16]. If, due to lack of ability or belief of lack of ability, a child is not able to play or compete with his or her peers, s/he will live that experience as a failure [6]. The physical experience of the body and its abilities has an enormous value for young people because it is a basic relational tool with peers and helps construct a solid sense of one's physicality that will stay with the person throughout adolescence and life [1]. For this reason, play and sport is and must be considered the primary means for promoting motor, cognitive and relational skills in children [10].

It is possible to improve self esteem by working directly on motor activity, directing games and exercises toward objectives that perfect and enrich movement capabilities within the child, making him or her more competent and improving interpersonal relations with his or her peers [19]. Motor activity in school is extremely important as it helps the child develop both physically and psychologically [3].

This is specifically true of nine year-olds who are about to enter adolescence - a period in which the relationship with the self and with one's body takes on very particularly characteristics [12]. Well planned, directed and carried out motor activities can certainly help children face this particular and often critical phase of life.

If sold self-esteem is constructed during childhood, the person will become a positive, well-adjusted and intelligent adult. For this to occur, the various education institutions and bodies must act on as many aspects of this as possible, since self-esteem concerns many aspects of a person's life. This research will demonstrate the validity of these theoretical assumptions.

\section{Materials and Methods}


Motor activity influences the development of healthy self-esteem. This is the underlying hypothesis of the experimental research carried out in two primary schools in the Perugia area - the Conservatorio Antinori and the $X X$ Giugno elementary school. In the first school, the research team selected a work group of 26 children (15 females and 11 males) from the fourth grade. In the second school the control group was made up of 22 fourth grade children ( 13 females and 9 males).

The study took place over six months, from September 2010 to March 2011. The control group participated only in testing activities at the beginning, mid-point and end of the research period while the work group was kept constantly active by a moderate motor activity with the help of the teacher. The group was introduced to some lesson plans in order to develop the basic motor schemes, the coordination and conditional capacities for the achievement of the motor education and control. During the activities they have been used codified, uncodified and makeshift tools.

In particular the study was divided into two learning units [14]. The first, Stiamo meglio insieme...perché giochiamo insieme! (Let's get along better together... because we're playing together!) took place from October to December and essentially proposed team and collective games to reinforce cooperation, positive interdependence, motor-skills problem solving, game tactics, fair play and respect for rules. The equipment used for this unit was the ball, both because the children preferred playing with balls and because it is a tool that promotes inclusion able to develop directly hand-eye coordination, balance and physical awareness of time and space.

The second unit was called Stiamo meglio insieme... perché ci sentiamo più forti! (Let's get along better together... because we feel stronger!) took place over two months and involved different types of games ranging from individual, collective, pair, movement, and rhythmic activities. This unit aimed specifically at consolidating lateral action, balance, and above all autonomy, determination, sense of responsibility and self-esteem.

Each learning unit aimed to promote specific relational motor objectives.

Motor objectives:

- Consolidation of basic motor skills schema;

- Development of segmented and inter-segmented coordination;

- Hand-eye and grapho-motor coordination;

- Improvement of balance and general dynamic coordination;

- Construction of notions of time and space.

- Relational objectives:

- Improvement of self-esteem of the children;

- Development of socialization and cooperation between the children;

- Reinforcement of autonomy in individual children.

To obtain statistical results that could validate the research hypothesis, the research team used systematic observation and analysis of internationally recognized tests. Specifically, the MOVIT test was used to monitor motor objectives, while the TMA test was used to monitor relational objectives. The first test evaluates childrens' motor skills through standardized exercises and tests that indicate the degree to which the child possesses specific functional pre-requisites. The MOVIT tests permit the delineation of the psycho-motor profile of the child through the evaluation of specific abilities. The functional prerequisites of movement analyzed are: tone and relaxation, balance and general dynamic coordination, segmentary and inter-segmentary coordination, hand-eye coordination, lateral action, construction of notions of time and construction of notions of space. Points attributed were 0 (if the task was not performed), 1 (if the task was performed with external assistance) or 2 (if the task was performed autonomously).

The TMA test, evaluates various aspects of the degree of self-esteem of the child. The aspects considered in this study were: physical, interpersonal, competence in the environment, emotiveness, attitude toward school, and attitude toward family. Each question on the test was answered on a scale of four possibilities: true, absolutely true, false and absolutely false, for a total of 150 items (25 for each aspect). Each answer was assigned a points according to the type of response.

\section{Results}

The administration of the motor and relational tests produced statistically analyzed numerical results that highlight important differences between the work group and the control group.

In the first MOVIT test, the total average for the control group was 1.70 , while in the second test the average was $1.74(+2.3 \%)$. In the work group, on the other hand, for the same test the first result was a total average of 1.70 while the second test produced a total average of 1.94, an increase of $14.3 \%$ (Figure 1, Figure 2).

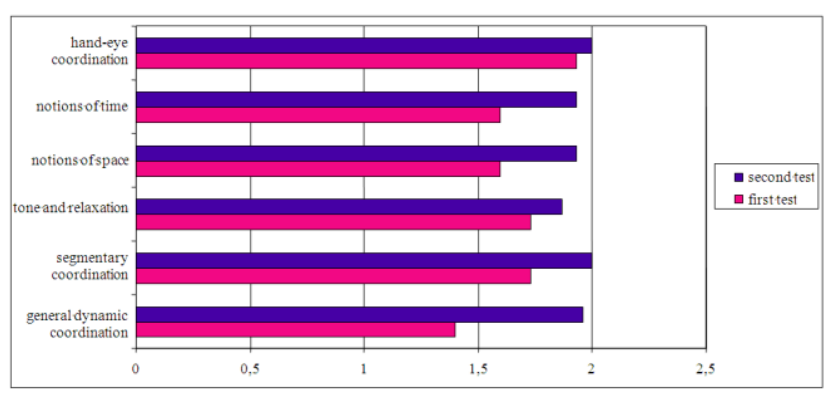

Figure 1. Comparison of motor tests in the control group

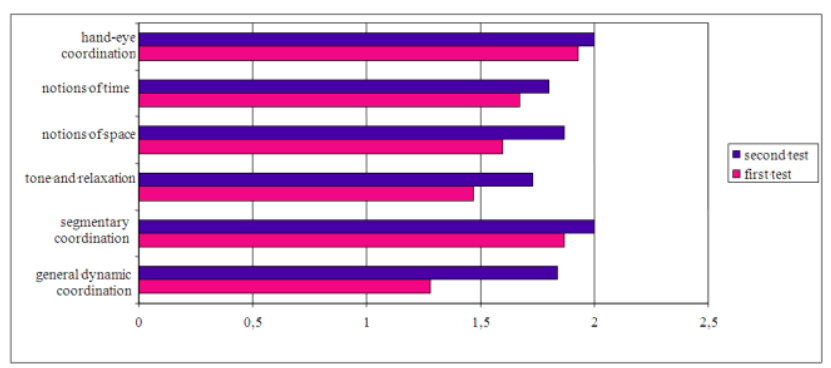

Figure 2. Comparison of motor tests in the work group

The TMA test evaluates global and partial self-esteem, and for this study produced the following results. The control group obtained an average result of 102 in September, and 107.2 in the second test carried out in March. This is an improvement of $5.2 \%$. For the work group, on the other hand, the total average for the first test 
was 99.8 , but increased $14.1 \%$ over the five month study period, reporting 113.9 in the second test carried out in March.

With respect to self-esteem, the control group appears more highly developed in the areas of competency with the environment $(6.5 \%)$, followed by interpersonal relationships $(5.8 \%)$, attitude toward school (4.7\%), physicality (4.4\%), emotional stability (4.3\%) and attitudes toward family (4.2\%).

The work group, on the other hand, obtained its highest scores in interpersonal relations $(26.5 \%)$, followed by competency with the environment $(24.4 \%)$, physicality (16\%), emotional stability $(13.3 \%)$, attitudes toward family $(2.9 \%)$ and attitudes toward school (2.2\%) (Figure 3, Figure 4).

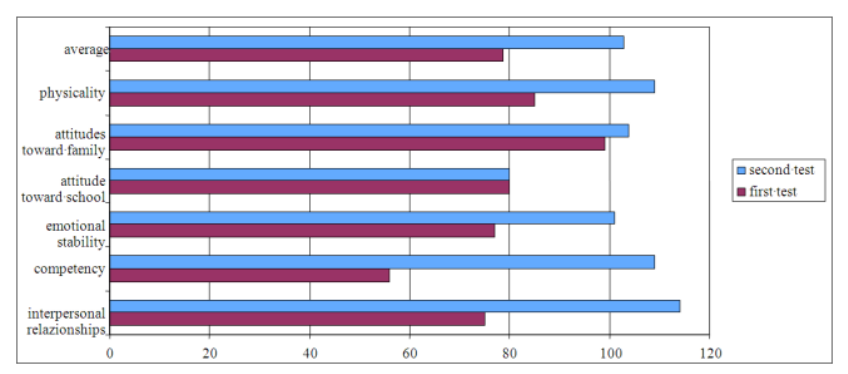

Figure 3. Comparison of relational tests in the control group

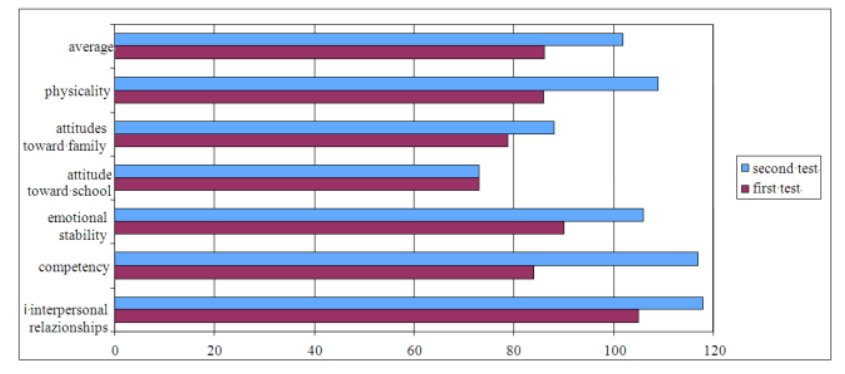

Figure 4. Comparison of the relational tests in the work group

\section{Discussion}

For the work group, the first test reported an average total of 1.70 with a standard deviation ${ }^{1}$ of 0.064 . A total number of 4 elements did not follow the general deviation parameter for the class (two high and two low). The test administered after 5 months to the control group reported an average of 1.64 with a standard deviation of 0,064 . The number of elements outside the deviation parameter were 5 (1 high and 4 low).

The control group reports: an total average increase from 1.70 to $1.74(+2,3 \%)$, no variation in standard deviation (0.064), a reduction in weak elements (from 2 to 1 ), and an increase in strong elements (from 2 to 5).

The class generally improved.

Figure 1 compares the results of the two motor tests (MOVIT) administered to the control group. There are

\footnotetext{
${ }^{1}$ Here, standard deviation indicates the interval of marks in which $66 \%$ of the students report. From the standard deviation it is possible to observe the homogeneity or lack thereof of the class. If the standard deviation is low, more children report closer to the same average and are therefore more aligned with each other.
}

observable improvements in the class between the end of September and March.

For the work group, on the other hand, the first test reports a class average of 1.70 with a standard deviation of 0.092. The total number of elements outside the deviation trend is 13 (6 low and 7 high).

The second test reports an average of 1.94 with a standard deviation of 0.039 and 12 elements outside the deviation trend (6 low and 6 high).

The work group report an increase in the total class average of $14.3 \%$ with a reduction of the standard deviation to 0.053 . The number of elements outside the deviation trend remains constant.

The gap between the strong and weak elements is marked, testifying to a relative lack of homogeneity in the class. This gap remained for the entire period of study regardless of the significantly elevated improvement in overall class performance.

Figure 2 compares the results of the two motor tests (MOVIT) in the work group - the first at the end of September and the second in March. In comparing the control group and the work group, the initial average is identical (1.70), but the second test reports an average increase 7 times greater in the work group with respect to the control group over the five month study period. The greater dishomogeneity of the work group does not seem to align with the lesser standard deviation. This effect may be explained by the fact that the elements are distributed in three primary groups (weak, moderate and strong) that alter the numerical significance of the deviation.

Figure 3 compares the results of the two relational tests (TMA) in the control group.

In the initial test, the control class reported a total average of 102.0 with a standard deviation of 8.7. The number of elements outside the deviation trend were $8(5$ low and 3 high). After 5 months, the average increased to 107.2 with a standard deviation of 6.8 The number of elements outside the deviation trend dropping to 6 (4 low and 2 high). The control class improved $5.2 \%$ with a slight mediation between strong and weak elements.

Figure 4 compares results for the two relational tests (TMA) in the work group.

The initial average for the work group was 99.8, with a standard deviation of 9.4. The number of elements outside the deviation trend was 7 (4 low and 3 high). After five months, the total average increased to 113.9 with a standard deviation of 6.5 . The number of elements outside the deviation trend remained the same.

This demonstrates a substantial increase in the total average $(14.1 \%)$ and a slight reduction in the standard deviation.

\section{Conclusion}

These results demonstrate that improvements in self esteem among children of the work group occurred precisely in the areas of operation of the project, that is -in areas of interpersonal relations, competence in the environment and physical competence.

From this it is possible to conclude that the underlying hypothesis of this study has been verified. The experiments produced positive results and affirm that motor activity influences the improvement of self-esteem. 
This theoretical and experimental work sheds light on how much self esteem is important to people, helping them feel adequate to situations, able to take new paths unafraid of not meeting expectations or not being able to face new situations [17]. Children construct their own sense of self over time, referring to their experienced emotions and to the image that others construct of [13]. When the family environment is fertile, when parents dedicate a great deal of time to the child and when they also impose specific and reasonable rules, step by step the child creates his or her sense of security [18]. At the same time, when the school or other educational institution fundamental to growth values the child by promoting him or her, supporting his or her ideas and giving space to his or her imagination, that institution contributes to the creation of good self-esteem that will stay with the child for the rest of his or her life [4]. As a place of interpersonal relationships and the construction of their characters, school is the perfect environment and ideal context for taking risks and through directed projects, passion and love aiming at the full psycho-physical development of the child so that he or she can develop to become a well-adjusted and trusting person to the fullest of his or her ability [15].

\section{Acknowledgement}

We would like to thank the school, the Headmaster, teaching staff and general staff, the parents and in particular all of the students who took part in the Educational Research Project - participating and having fun at the same time in the spirit of cooperation and creativity and demonstrating great responsibility and maturity. "Together" we were able to grow in the context of an educational community full of stimulation and strong motivation by believing that a well planned project can reach positive results through the enthusiasm and good will of everyone while respecting the individuality of each participant. We are sure that this team spirit must be present among colleagues and those responsible for communicating research results to further internal and external cooperation in studies that have children as participants. Communicating about, comparing and discussing experiences helps understand children better and helps them have better lives. In all contexts, adults have the obligation to raise to the best of their ability the men/women/citizens of tomorrow.

\section{References}

[1] Accame F., E se ti dico sport?, Polistampa, Firenze, 1998.

[2] Bandura A., Autoefficacia, Erickson, Trento, 2001.

[3] Biagioli R., Zappaterra T., La scuola primaria. Soggetti, contesti, metodologie e didattiche, ETS, Pisa, 2010.

[4] Bonino S., Reffieuna A., Psicologia dello sviluppo e scuola primaria. Dalla conoscenza all'azione, Giunti, Firenze, 2007.

[5] Braken B., TMA. Test di valutazione multidimensionale dell'autostima, Erickson, Trento, 2005.

[6] Calcerano L., Casolo F. (2008). Educazione motoria e sportiva, Editrice La Scuola,. Brescia, 2008.

[7] Cottini L., MOVIT Programma per l'educazione psicomotoria di allievi normodotati e con problemi, Tecnoscuola, Gorizia, 1996.

[8] Danielle L., Lise S., L'autostima dei ragazzi. Da 6 a 12 anni, Edizioni San Paolo, Milano, 2008.

[9] Dentale F., La dimensione implicita dell'autostima. Un contributo di ricerca con l'utilizzo dell'Implicit Association, Franco Angeli, Milano, 2008.

[10] Federici A., Teoria, tecnica e didattica dell'attività motoria per l'età evolutiva, Asterisco, Urbino, 2008.

[11] Harter S., The construction of the self. New York, Guildorf Press, 2001.

[12] Iavarone M. L., Abitare la corporeità. Dimensioni teoriche e buone pratiche di educazione motoria., Franco Angeli, Milano, 2010.

[13] Mondato F., John Dewey e Jean Piaget, Il valore dell'esperienza. Conoscenza, metodi, azione educativa., Roma, Conoscenza Edizioni, 2008.

[14] Pedon A., Gnisci A., Metodologia della ricerca psicologica, Il Mulino, Bologna, 2004.

[15] Petter G., Psicologia e scuola dell'infanzia. Il bambino fra i tre e i sei anni e il suo ambiente educativo, Giunti, Firenze, 2009.

[16] Plummer D., La mia autostima, Erickson, Trento, 2008.

[17] Pope A., McHale S., Craighead E., Migliorare l'autostima, Erickson, Trento, 2008.

[18] Santrok J. W., Psicologia dello sviluppo, Mc Graw Hill, Milano, 2008.

[19] Sunderland M., Aiutare i bambini... con poca autostima. Attività psicoeducative con il supporto di una favola, Erickson, Trento, 2007.

[20] Valentini M., Castriconi S., L'altro linguaggio, MargiacchiGaleno Editore, Perugia, 2007.

[21] Vianello R. Psicologia dello sviluppo, Edizioni Junior, Bergamo, 2009. 